\title{
Centrilobular Opacity
}

National Cancer Institute

\section{Source}

National Cancer Institute. Centrilobular Opacity. NCI Thesaurus. Code C124061.

A radiologic finding indicating the presence of radio-opaque areas in the central parts of lung lobules. 